\title{
Comment on "Blood Flow Mimicking Aneurysmal Wall Enhancement: A Diagnostic Pitfall of Vessel Wall MRI Using the Postcontrast 3D Turbo Spin-Echo MR Imaging Sequence"
}

W e read with interest the article "Blood Flow Mimicking Aneurysmal Wall Enhancement: A Diagnostic Pitfall of Vessel Wall MRI Using the Postcontrast 3D Turbo Spin-Echo MR Imaging Sequence" ${ }^{\text {1 }}$ published in the American Journal of Neuroradiology in 2018.

We would like to congratulate the authors for a very wellwritten article on a subject that may strongly affect the interpretation of vessel wall enhancement obtained on $3 \mathrm{~T}$ brain MR imaging.

Several studies ${ }^{2,3}$ performed on various MR imaging units have demonstrated that aneurysm wall enhancement may be a marker for instability, thus a noninvasive biomarker for patient counseling and therapeutic decision-making. In this article, the authors demonstrated that part of the enhancement may be due to intra-aneurysmal slow blood flow because the wall enhancement decreased and sometimes vanished when a motion-sensitized driven equilibrium sequence was used. We agree that T1shortened enhanced blood signal near the wall may cause nonspecific wall enhancement-like signal. However, in our opinion, the observation that slow-flow artifacts may contribute to the observed wall enhancement does not invalidate the fact that contrast enhancement is strongly linked to aneurysm status. ${ }^{2}$

Computational fluid dynamics studies ${ }^{4}$ demonstrated that slow flow contributes to low wall shear stress, hence promoting aneurysm wall inflammation. Slow flow, low wall shear stress, and wall inflammation probably all contribute to the observed enhancement. We agree that histopathologic confirmation is

http://dx.doi.org/10.3174/ajnr.A5777 strongly warranted to confirm the inflammatory nature of aneurysm wall enhancement.

\section{REFERENCES}

1. Kalsoum E, Chabernaud Negrier A, Tuilier T, et al. Blood flow mimicking aneurysmal wall enhancement: a diagnostic pitfall of vessel wall MRI using the postcontrast 3D turbo spin-echo MR imaging sequence. AJNR Am J Neuroradiol 2018;39:1065-67 CrossRef Medline

2. Edjlali M, Ben Hassen W, Boulouis G, et al. Circumferential thick enhancement on high resolution vessel wall MRI is a biomarker with high specificity of intracranial aneurysm instability. Radiology 2018 Jul 3:172879. [Epub ahead of print] CrossRef Medline

3. Edjlali M, Gentric JC, Régent-Rodriguez C, et al. Does aneurysmal wall enhancement on vessel wall MRI help to distinguish stable from unstable intracranial aneurysms? Stroke 2014;45:3704-06 CrossRef Medline

4. Xiang J, Tutino VM, Snyder KV, et al. CFD: computational fluid dynamics or confounding factor dissemination? The role of hemodynamics in intracranial aneurysm rupture risk assessment. AJNR Am J Neuroradiol 2014;35:1849-57 CrossRef Medline

$$
\begin{array}{r}
\text { (D) Edjlali } \\
\text { Department of Neuroradiology } \\
\text { Université Paris Descartes Sorbonne Paris Cité } \\
\text { Centre Hospitalier Sainte-Anne } \\
\text { Paris, France } \\
\text { DP. Turski } \\
\text { Departments of Radiology and Medical Physics } \\
\text { University of Wisconsin } \\
\text { Madison, Wisconsin } \\
\text { C. Oppenheim } \\
\text { O. Naggara } \\
\text { Department of Neuroradiology } \\
\text { Paris, France }
\end{array}
$$
Université Paris Descartes Sorbonne Paris Cité, Centre Hospitalier Sainte-Anne 